\title{
Radical Prostatectomy in the Robotic Era. Comparison of Three Different Methods: Retropubic, Robotic and Perineal
}

\section{Robotik Çağda Radikal Prostatektomi. 3 Değişik Metodun Karşılaştırılması: Retropubik, Robotik ve Perineal}

\author{
Burak Özkan, Enis Rauf Coşkuner \\ Acıbadem University Faculty of Medicine, Department of Urology, İstanbul, Turkey
}

\begin{abstract}
Prostate cancer is the second most prevalent cancer among men and is the 6th cancer type leading to death. Starting with the use of PSA screening, there has been a steep increase in the number of cases diagnosed with and treated for localized prostate cancer. Radical prostatectomy use has increased following the increase in the number of cases and has become the golden standard for surgical procedures for their treatment. For over 50 years, while open retropubic and perineal methods have been used separately, advantages and disadvantages of each method have been expressed in official and unofficial grounds. The use of nerve-sparing radical prostatectomy that began particularly after the clearer definition of the neurovascular bundles and the anatomy of the prostate by Walsh and the improvements in continence and potency has proved open radical retropubic prostatectomy (RRP) more advantageous. The da Vinci Surgical System (Intuitive Surgical, Sunnyvale, CA, USA), developed to qualify disadvantages of laparoscopy in radical prostatectomy, came into use in 2000. With Abbou's identification of first robotic assisted radical prostatectomy (RARP), it finds increasing areas of application. Still there is need for further comparison of especially the three methods (RPP, RRP, and RARP) in prostate cancer treatment with more patients and longer follow-up periods. The objective of the first part of this paper is to provide a brief comparison of RRP and RARP results and in the second part we will discuss the perineal radical prostatectomy.
\end{abstract}

\section{Key Words}

Prostate cancer, retropubic radical prostatectomy, robotic radical prostatectomy, perineal radical prostatectomy

\section{ÖZET}

Prostat kanseri, erkekler arasında en yaygın ikinci kanser ve ölüme yol açan 6. kanser tipi. PSA görüntüleme kullanımıyla birlikte, lokalize prostat kanseri için tanı koyulan ve tedavi edilen vakalar keskin şekilde arttı. Olgu sayısında artışı takiben radikal prostatektomi kullanımı yükseldi ve tedavi için cerrahi prosedürlerde altın standarda dönüştü. Elli yıldan fazla bir süredir açık retropubik ve perineal metotlar ayrı ayrı kullanılırken, her metotun avantaj ve dezavantajları resmi ve gayri resmi alanlarda dile getirildi. Nörovasküler demetlerin ve prostat anatomisinin Walsh tarafından açıç̧a ortaya konmasından sonra başlayan sinir koruyucu radikal prostatektomi kullanımı ve kontinans ve potansideki gelişmeler, açık radikal retropubik prostatektomiyi (RRP) daha avantajı kıldı. The da Vinci Surgical System (Intuitive Surgical, Sunnyvale, CA, USA) 2000'de kullanıma giren radikal prostatektomideki laparoskopinin dezavantajlarını hafifletmek için gelişti. Abbou'nun ilk robotik destekli radikal prostatektomiyi (RARP) tanımlamasıyla bu, artarak uygulama alanları buluyor. Hala prostat kanseri tedavisinde özellikle bu üç metodun (RPP, RRP ve RARP) daha fazla hastayla ve daha uzun takip periyodlarıla ileri seviye karşılaştırmaya intiyacı vardır. Bu makalenin ilk bölümünün amacı retropubik radikal prostatektomi (RRP) ve robotik destekli radikal prostatektomi (RARP) sonuçlarında geniş çaplı karşılaştırma sağlamaktır ve ikinci kısımda perineal radikal prostatektomi ele alınmıştır.

\section{Anahtar Kelimeler}

Prostat kanseri, retropubik radikal prostatektomi, robotik radikal prostatektomi, perineal radikal prostatektomi

\section{Introduction}

Prostate cancer is the second most prevalent cancer among men and is the $6^{\text {th }}$ cancer type leading to death. The estimated numbers for 2008 are 899.000 new cases and 258.000 deaths (1). For 2007, these numbers are 218.890 and 27.050 , respectively (2). With the aging world population, the burden of prostate cancer is expected to increase. Considering the global population increase and the aging pace, 1.7 million new prostate cancer cases and 499.000 deaths due to the disease are expected in year 2030 (1).

Widely accepted risk factors of prostate cancer are age, African race, and family history of prostate cancer (3). There is an increase in the incidence rate of prostate cancer specifically due to use of prostate specific antigen (PSA) in asymptomatic men's screenings (4).

Various surgical approaches can be used for a specific surgical procedure in urology. Each approach can have different roles,

\section{Correspondence}

Burak Özkan MD, Acıbadem University, Faculty of Medicine Department of Urology, İstanbul, Turkey

E-mail: burakozkandoc@gmail.com Phone: +90 5324980495

Journal of Urological Surgery. 
advantages and disadvantages based on the shape of the incision, method of dissection and the tools used. However, no single approach can precede other approaches as the leading approach, or no such approach has yet been discovered (5).

In United States (US), starting with the use of PSA screening, there has been a steep increase in the number of cases diagnosed with and treated for localized prostate cancer. Radical prostatectomy use has increased following the increase in the number of cases and has become the golden standard for surgical procedures for their treatment (6). The goal of this procedure is to provide total resection of malignant tissue, reduce complications, and maintain urinary continence and erectile functions. Various methods such as brachytherapy, radiotherapy, cryotherapy and high-intensity focused ultrasonography (HIFU) have been used as alternatives to surgical interventions in localized prostate cancer treatment within the past ten years. According to the American Urology Association's recommendations, in newly diagnosed localized prostate cancer cases, the patient should be offered all treatment options (7). Despite continuously evolving with various technical modifications and developments, radical prostatectomy constitutes the most important method in surgical treatment of prostate cancer since Hugh Hampton has completed the first perineal prostatectomy in 1905. Radical prostatectomy, like some other surgical procedures, can be carried out via different approaches. For over 50 years, while open retropubic and perineal methods have been used separately, advantages and disadvantages of each method have been expressed in official and unofficial grounds. Radical perineal prostatectomy can be performed via subsphincteric or suprasphrincteric approaches while retropubic radical prostatectomy can be performed via retrograde or antegrade approaches (5).

The use of nerve-sparing radical prostatectomy that began particularly after the clearer definition of the neurovascular bundles and the anatomy of the prostate by Walsh, and the improvements in continence and potency have proved open radical retropubic prostatectomy (RRP) more advantageous (8). However, the inconsistent results of $R R P$, use of laparoscopy in urology, and less invasive methods like brachytherapy caused the development of laparoscopic radical prostatectomy (LRP) and accelerated initiation of its use (9). In addition to the conventional advantages of minimally invasive surgery, LRP is considered advantageous because it can attain similar oncologic and functional results as open radical prostatectomy with less blood loss, shorter hospital stay and lower rates of postoperative morbidity. However, LRP also has disadvantages as it has a 2-dimensional view, has an extended learning period, has limited ergonomics, requires advanced laparoscopic skills, and is a difficult procedure with respect to dissection and sutures (10).

The da Vinci Surgical System (Intuitive Surgical, Sunnyvale, CA, USA), developed to overcome the disadvantages of laparoscopy in radical prostatectomy, came into use in 2000. With Abbou's identification of first robotic assisted radical prostatectomy (RARP), it finds increasing areas of application (11). The distinct advantages of this method are that it has depth perception, provides approximately a 10-fold magnification of the image, its tools have extra mobility as they have junctions, its movements can be controlled via finger and wrist movements, comes with a tremor filter, has an ergonomic working position and a shorter learning period compared to laparoscopy (12).
Lee reported that of the radical prostatectomy surgeries performed in US in 2007,60\% were performed with robotic and that this ratio increases each year (13). Every year, more urologists in both academic and private practice have started to prefer this method.

The objective of the first part of this paper is to provide a brief comparison of RRP and RARP results and in the second part we will discuss the perineal radical prostatectomy.

\section{Comparison of Open Radical Prostatectomy and Robotic Radical Prostatectomy}

\section{Patient Selection}

Aside from a few exceptions, patients who are candidates for open radical prostatectomy are also candidates for RARP (5). Under normal conditions, patients with localized malignancy and who have been diagnosed via biopsy are treated with radical prostatectomy. Even in patients with suspected extracapsular extension, RARP remains a treatment option along with RRP. However, in these cases, a lateral prostate dissection must be made and this should be considered while preparing the surgical plan (14).

Obesity is not a contraindication for RARP. However, it is technically difficult to perform on individuals with morbid obesity, those who have a body mass index (BMI) of 35 or higher (15).

Previous abdominal surgeries do not constitute a contraindication for RARP either. In Menon et al.'s series, one third of the patients had history of abdominal surgery. They reported that no problems were encountered when the robotic ports were properly placed. Interestingly, in 5-10\% of patient with no surgical history, adhesions can be observed in the abdomen (15). Mobilization of the bladder is difficult in patients with previos history of partial cystectomy, ureteral reimplantation, ureterolithotomy, sigmoid colon surgery involving the perivesical space. In such cases RRP should be preferred. Appendectomy is not a contraindication for RARP. RARP can be performed in presence of umbilical hernia as well but the camera port should be placed with the open technique. The hernia can be repaired after the surgical specimen is removed (5). RARP should be the preferred method in patients with laparoscopic inguinal hernia repair history, because the patch used requires incision in RRP.

A large prostate size is not a contraindication for RARP either. RARP can be performed when the volume of the prostate exceeds $150 \mathrm{~mL}$. The robotic method can be used in large middle lobe presence as well. Robotic technique is also known to ease apical dissection in patients with small prostates (16).

Patient positioning is crucial in RARP; the pressure on thorax due to extensive Trendelenburg positioning can lead to problems for patients with cardiac and pulmonary comorbidities. RARP is not appropriate for these patients (15). History of organ rupture, radiotherapy and peritonitis are relative contraindications of RARP (12).

\section{Operation Duration}

It is difficult to compare the duration of operations between series. Especially in RARP, the time that the robot set up and pelvic lymph node dissection takes can lead to confusion. While it is expected that a surgeon's learning curve will impact the duration of surgery, the 
learning curve of the operational room staff also has an impact on the time spent for setting up the robot and the time spent until the operation begins. The reported average durations of robotic surgery series are between 141 and 540 minutes $(17,18,19)$. In Patel et al's 200-patient series, the average duration of the first 50 cases was 202 minutes, which declined to 141 minutes for the last 50 cases. This duration is 90 minutes for the same group when the case number increases to 1000 (19). Ahler et al. also report a decline in the operation duration with increased experience with an average of 207 minutes in their 45-patient series where the average for the last 10 patients was 184 minutes (17). The average reported operation durations for RRP on the other hand are between 135 and 204 minutes. While RARP duration declines with increased experience, it can still be considered long compared to RRP (20). Another paper reported of no difference between RRP and RARP durations, which were performed by the same surgeon in the same center (21).

\section{Blood Loss and Transfusion}

As in any other surgical intervention, there can be a considerable amount of blood loss in prostatectomies as well. The blood loss can lead to a necessity of transfusion and this transfusion can cause reactions. At the same time, intraoperative bleeding can contaminate the surgical area and can further complicate the technique used (12). Transfusion rates are not always proportional with the amount of blood loss. While a patient does not receive transfusion with a considerable amount of blood loss, less blood loss may require transfusion due to other possible complications and general disorders that the blood loss may cause. In radical prostatectomies, bleeding usually occurs in venous sinuses. In RARP, the tamponade effect of pneumoperitoneum reduces bleeding. The magnified view of the surgical area eases detection of veins that pose bleeding risk and enables the surgeons to take precautions. While the estimated blood loss is between 150 and $300 \mathrm{ml}$ in RARP series, this amount is approximately 500 to $800 \mathrm{ml}$ in RRP. Accordingly, transfusion rate is $1.9 \%$ in RARP while it is $5.1 \%$ in $\operatorname{RRP}(22,23,24)$. The reported transfusion rate of majority of the RARP series in US is $0 \%$. Menon et al. report no transfusion in their 1100-patient RARP series (15). Tewari et al. on the other hand report transfusion rates of $67 \%$ and $0 \%$ in 100-patient RRP and 200-patient RARP series, respectively (25).

\section{Functional Results}

The greatest advantage of minimally invasive methods is the shorter recovery period. Shorter recovery period is defined as less postoperative pain, shorter hospital stay, shorter duration of catheterization, and quicker return to daily life.

\section{Postoperative Pain}

Because small incisions are used in all of the laparoscopic surgeries, there is a general trend that there will be less postoperative pain with them. Few studies compared the RRP and RARP methods with respect to postoperative pain. These studies, in general, reported that the postoperative pain in RARP is either equivalent to or less than the postoperative pain in RRP. In Menon et al.'s study that used a visual analog pain scale, the average pain score on postoperative day 1 among RARP patients was 3 (1-7) while this score was 7 (4-10) among RRP patients (25). In Webster et al's study using a Likert scale for pain, the average pain scores on the day of surgery for 314 RRP and 154 RARP patients were 2.88 and 2.52, respectively; no statistically significant difference was found between the groups. On postoperative day 1 of the same study, RRP group's pain scores were reportedly better than those of the RARP group (1.58 for RRP; 2.92 for RARP). However on postoperative day 14 , no significant difference was found between the groups' pain scores (2.10 for RRP; 2.81 for RARP) (26).

\section{Duration of Hospital Stay}

Duration of hospital stay is considered an indicator of quick recovery and constitutes one of the criteria that patients use to evaluate the success of surgery. When Patel et al. compared the duration of hospital stay of 374 RRP patients with that of 629 RARP patients; the average duration for open surgery was 1.23 days and 1.17 days for robotic surgery. While $94.3 \%$ of the RRP patients were discharged on the day of surgery or on postoperative day 1, for RARP patients discharged on the day of surgery or on postoperative day 1 , this rate went up to $97.5 \%$ (27). A study by Joseph et al. reports that the average duration of hospital stay is 64.5 hours for RRP patients and 25,4 hours for RARP patients (9).

Duration of hospital stay for RARP patients is generally reported to be 1.08 to 5.05 days. With increased experience with the equipment, this duration decreases down to between 1.08 and 1.5 days (19). Ahler et al. report that when the same surgeon performs RRP and RARP, the average hospital stay is 52.8 and 25.9 hours, respectively (21). Results supporting their study were reported by Menon et al., stating that the hospital stay were 3.5 and 1.2 days for RRP and RARP (28).

\section{Duration of Catheterization}

RARP eases the performance of ureterovesical anastomosis by providing a better image, with use of tools that allows for higher mobility and can be manipulated by the fingers and the wrist. Watertight anastomosis allows for an earlier removal of the Foley catheter. The average time until catheter removal in RARP series is 3 to 18 days. When the series with less than 40 patients are excluded, this duration becomes 4.2 to 7.2 days. This might indicate that ureterovesical anastomosis can be performed more safely with increased experience. In Ahlering et al's series, the average time until catheter removal was reported to be 7 days for RARP and 9 days for RRP, though no significant difference was found between the two groups. Tewari et al. on the other hand, found that the average catheterization duration is twice as long in RRP than in RARP (15.8 days; 7 days) (25). Menon et al.'s series results yielded that the average catheterization after RARP is 4.2 days (28). When RARP and RRP are compared, catheterization is generally shorter in robotic series (29).

\section{Oncologic Results}

The main purpose of radical prostatectomy is to remove the entire prostate with negative surgical margins, and to be able to achieve satisfactory oncologic results. For RRP, in localized prostate cancer, reported 10-year patient control rates are $65-70 \%$ and the cancer specific survival rates are reaching 97\% (30). While there are records for 15-year reports of RRP, there are limited follow-up results for minimally invasive methods. 
Most widely used parameters in evaluation of post- radical prostatectomy oncologic results are biochemical progression and surgical margin positivity (SMP) (6). Early increases in PSA level, can be evaluated as an early indicator of biochemical progression. Positive surgical margin means that cancer cells are present on the stained section of the resected part, which constitutes a biochemical recurrence risk (6).

While lack of tactile sensation in RARP is considered a handicap of the method, enlarged 3 dimensional imaging, minimal bleeding and ease of dissection due to less bleeding are considered to be advantages of RARP (12).

Reported SMP in RRP series is 12 to $15 \%(31,32)$. In a literature review by Weider et al. the range of the reported PSM was 0 to $77 \%$. Within the same study, SMP rates for T2a and T2b were $0-38 \%$ and 11-77\%, respectively (33). SMP rates after RARP on the other hand are $0-36.4 \%$. When the cases are grouped based on the stages, SMP rates for $\mathrm{T} 2 \mathrm{a}$ is $0-16.7 \%$, for $\mathrm{T} 2 \mathrm{~b}$ is $0-33.3 \%$, for $\mathrm{T} 3 \mathrm{a}$ is $0-81.8 \%$, for T3b is 20-50\% (for T3 in general is 0-75\%), and for T4 is 33.3-66.6\% (12). These findings are similar to those of RRP in general. In a study where Ahlering et al. evaluated the surgeries performed by the same surgeon, they reported SMP rates of 20\% in RRP and 16.7\% in RARP (21). Within the same series, SMP rates for T2 diseases for RRP and RARP were 9.1\% and 4.5\%, respectively. Patel et al., in another study, reported an SMP rate of $9.4 \%$ in a 500-patient series, in which this rate was observed to be $13 \%$ for the first 100 cases, $8 \%$ for cases $101-200,13 \%$ for cases 201-300, 5\% for cases 301-400, and 8\% for cases 401-500. With respect to the stage of disease, the rates were 2\% for T2a, 4\% for T2b, 2.5\% for T2c, 23\% for T3a, 46\% for T3b. For T4a staged cases, the reported SMP rate was 53\%. In other words, while SMP rates for RARP in organ-confined cases was 2.5\%, this rate is around $31 \%$ in not organ-confined diseases. When localization of SMP in the pathology specimens were examined, of the SMPs (47 cases total). Twenty-six (56\%) posterolateral, 4 (8.5\%) apex, 4 (8.5\%) bladder neck, 2 (4\%) seminal vesicle, and 11 (23\%) multifocal cases were identified (34).

Di Marco et al. reported SMP rates of $18.6 \%$ for RRP and $16.5 \%$ for RARP (35). Smith et al. retrospectively evaluated 200 patients from each group, SMP rate for RARP group was 15\% and for RRP group it was 35\%. They identified that especially in patients with T2 stage and a Gleason score $\leq 6$, SMP rate was significantly lower in RARP (36). Badani et al., in their study and 5-year follow-up of RARP cases, have reported a SMP rate of 13\%. This rate was 12\% in first 200 cases and has declined to $5 \%$ in the last 200 cases $(p<0.05)$ (37). Jaffe et al. report that SMP rates in RARP decline as the experience of the surgeon increases. In their series of 278 patients, the SMP rate was $58 \%$ in the first 12 patients, decreased to $23.3 \%$ in the second group of 176 patients, and further decreased to $9 \%$ in the last group of 89 patients (38).

A meta-analysis by Novara et al., published in 2012, reports that an average of 12-19 lymph nodes are removed during a RARP and that the positive lymph node rate is at $11-24 \%$. When the lymph node dissection template size is enlarged, the complication rates are reported to increase compared to the smaller dissections. Post-operative lymphocele development is reported to be more common among patients who have undergone extraperitoneal lymph node dissection compared to those who have undergone transperitoneal dissection (6\% vs 4\%). There are findings showing that FloSeal application to the surgical area after extraperitoneal lymph node dissection decreases Iymphocele development. In the meta-analysis evaluation of this team, SMP post-RARP is 6.5-32\% with an average of 15\%. Mean SMP is 9\% (4-23) among pT2 patients, 37\% (29-50) among pT3 patients, and 50\% (40-75) pT4 patients. The SMP distribution by anatomic localizations among these patients were $5 \%$ for apex, $0.6 \%$ for anterior, $1.6 \%$ for bladder neck, $2.6 \%$ for posterolateral, and $2.2 \%$ for multifocal. SMP is not influenced by high BMI, enlarged prostate, prior abdominal surgery, or benign prostate hyperplasia and those with middle lobe. The factors reported to impact SMP are PSA, pT stage, biopsy gleason score, the education and prior radical prostatectomy experience of the surgeon, nerve-sparing surgery type, and the approach used for controlling dorsal vein complex. When evaluated with respect to biochemical recurrence, it has been reported that there is no difference between open radical prostatectomy and RARP when experienced surgeons perform the surgery. Since no clear data have been put forth, long-term follow-up results of RARP in terms of cancer-specific are not known yet (39).

\section{Lymph Node Dissection}

The extent of lymph node dissection (LND) during radical prostatectomy is still a topic of discussion $(40,41)$. Cooperberg et al. compared the lymphadenectomy results of robotic and open surgery, and reported that LND was performed in $47.8 \%$ of open surgery cases and in $31.8 \%$ of robotic surgery cases. In time, there was an increase in the number of LNDs performed in both groups (39). In a group of patient with similar risks, while approximately 14.4 lymph nodes were removed in RRP surgeries, there were an average of 9.3 nodes removed in RARP surgeries (40). In the Memorial Sloan Kettering experience on the other hand, a larger area of lymph nodes was removed via RARP extended pelvic node dissection (19 on average). In RRP, there were 14 nodes removed (41). The same group has also reported higher rates of node metastasis in RARP; 13\% for RARP and 9\% for RRP. Atuğ et al. reported that pelvic lymph node dissection performed during RARP does not cause a significant difference in duration of hospital stay, average blood loss, duration of operation, cost of operation and complications (42). Torrey et al's study, conducted in City of Hope Cancer Center with 44 patients in moderate and high risk groups, reported average removal of 17.2 (9-34) lymph nodes and 13.6\% positivity in lymph nodes after extended pelvic node dissection (43). The authors report that failure to perform open or robotic pelvic node dissection can lead to sub-optimal oncologic results and considerably higher rates of biochemical recurrence (43).

\section{Continence}

One of the primary surgical goals during radical prostatectomy is to ensure continence continuity. This is one of the parameters that patients pay particular attention to while evaluating treatment options. The development of surgical technique, introduction of the mucosa against mucosa methodology, preservation of functional urethral length are important in both preserving continence and preventing stenosis. Younger age, preservation of neurovascular bundles, and absence of preoperative urethral stenosis are important factors in preserving continence postoperatively (12). 
Incontinence rates are as high as 50\% in earlier RRP series (44). Walsh et al. report continence (not using a pad for the past 4 weeks) rates for the 3rd month as 54\%, for the 6th month as $80 \%$, and for the 12 th and 18 th months as $93 \%$ (45). Penson et al. reported continence rates of 90\% for 24th month and 88\% for 60th month for their 1288 patients who underwent RRP (46). For his 3477-patient RRP series, Frato reported a continence rate of 93\% (47). Lepor et al., also reported continence rates from their patients for month $3,6,12$, and 24 as 74\%, 89\%, 92\% and 97\%, respectively (48).

There are opinions suggesting that the return to continence is quicker after RARP. This is achieved by better views of the prostate apex, which leads to better separation of the urethral sphincter from the prostate, preserving urethral length, and better ensuring hemostasis that helps prevent blood flow disorders that may occur in the sphincter. First week, 1st month, and 3rd month post-RARP continence rates reported by Ahlering et al. are $33 \%, 63 \%$, and $81 \%$, respectively (17). Another comparative study conducted by the same study team reported that RRP and RARP did not differ with respect to continence rates (75\%, 76\%) (21).

Tewari et al's study on the other hand reports that return to continence occurs sooner after RARP, and that 50\% of patients are continent on day 44 after RARP, while continence is achieved on postoperative day 160 in RRP (25). Pasticier et al. report that $80 \%$ of their patients are continent by day 9, while Binder and Kramer report that 50\% of their patients are continent by the 1st month $(49,50)$. Menon et al. report a continence rate of $96 \%$ by the third month (51). Patel, in his 200-patient series, reported continence rates of $47 \%, 82 \%, 89 \%$, $92 \%$, and $98 \%$ for months $1,3,6,9$, and 12 respectively (19). BMI is an important parameter in return to continence after RARP; while continence rate is $91 \%$ by month 6 among those with BMls $<30$, this rate is $47 \%$ among those with BMls $>30$ (52).

\section{Erectile Function}

Post-radical prostatectomy erectile dysfunction is considered to be caused by damaged neurovascular bundles. Neurovascular bundles can be damaged in various ways. Direct incision, hemostatic suture, clip usage, thermal damage or trauma on the neurovascular bundles may cause this damage. Younger age, preservation of neurovascular bundles, and good preoperative potency are important factors in preserving erectile function postoperatively (53). Even after nervepreserving approach has been defined, post-RRP return of erectile function rate varies; this is also impacted by the surgeon's capability and how erectile dysfunction is defined (12). While potency rates post-RRP are reported to vary between $62-68 \%$ by larger scale institutions, patient reports vary between 10-30\% (54). In Quinlan et al's RRP series, potency rate was 90\% among patients under the age of 50, one or two neurovascular bundles of who were preserved (53). In the same series, this rate declines dramatically among the patients over the age of 50, especially if the neurovascular bundles have not been preserved.

Walsh defines potency as ability to have sexual intercourse with or without using sildenafil citrate, and the reported potency rate for months $3,6,12$, and 18 in his series are $38 \%, 54 \%, 73 \%$ and $86 \%$ (46).

In RARP series, potency rates vary between $79-80 \%$ (55). Patel et al report that $78 \%$ of the patients who were potent preoperatively and had one- or two-way nerve preservation surgery were potent by the end of the first year (55). In Badani et al's follow up of their series, they reported reaching 79.2\% rate of potency (36). Menon reports first and second year potency rates as 70\% and 100\% (15). Having less nerve damage in RARP is considered to be impacting surgery results positively. According to this view, having antegrade dissection and enlarged imaging lead to not making damaging moves on the nerves, less blood loss, not making dissection mistakes due to bleeding, and no undesired suture, clip or incisions. In the 565-patient series of Tewari et al., 82\% of patients under 60 years of age who were potent preoperatively reported having sexual activities and by the 6th month, $64 \%$ reported being able to have sexual intercourse. These rates for the patients over 60 years of age within the same group were 75\% and $38 \%$, respectively (25). These findings support Walsh's RARP findings. In Tewar' et al's study comparing 200 RARP and 100 RRP procedures, post-RARP return to potency was reported to be quicker than RRP; while $50 \%$ potency rate was achieved in 180 days after RARP, this rate was obtained in approximately 440 days after RRP $(p<0.05)(25)$. Both Menon and Ahlering report an increase in potency rates with increased use of scissors and bipolar electrocoagulation in the da Vinci system especially while performing posterior dissections $(56,17)$.

In a meta-analysis by Ficarra et al. on post-RARP potency, the potency rates at the end of a 12-month follow-up are reported to be 70-80\%. They found that potency recovery is faster among these patients when compared to open radical prostatectomy. The potency rates reported in months 3,6,12, and 24 are 50\%,65\%, 70\%, and 79\%, respectively. The reported independent risk factors for predicting post-operative erectile dysfunction risk are age of the patient (>60 years), post-operative potency condition, comorbidity index, expansion of nerve-sparing surgery, Charlson score $>1$, and the IIEF5 score. Potency rates are highest among patients who are young, potent post-operatively without comorbidities, and have undergone bilateral nerve-sparing surgery. In the meta-analysis compiled by the same team, it is reported that the potency condition is better among patients who have undergone bilateral nerve-sparing surgery than those who have undergone unilateral nerve-sparing surgery, that there was no difference between interfacial and intrafacial in terms of dissection plans, and that athermal dissection and unclipped dissection are important in sustaining potency.

However, there is still need for further prospective drandomized studies comparing the potency results of RRP and RARP $(57,58)$.

\section{Complications}

Today's better understanding of prostate anatomy leads to better surgery results and less adverse events regardless of the radical prostatectomy method used. Intraoperative and postoperative complication rates of RARP are $0-1 \%$ and $0-13 \%$, respectively $(18,19,21)$. However, postoperative complication rates (26.3\%) are higher among obese (BMI>30) patients (52).

\section{Intraoperative}

The major intraoperative complications associated with radical prostatectomy are injuries of the rectum, urethra, and nerves (obturator, femoral). Rectal injury rates are $0.05-2.5 \%$ in RRP series and $0-1 \%$ in RARP series $(59,19)$. Intestinal injury rates, excluding the rectum, are seen in $0-0.95 \%$ of RARP cases (60). While the urethral 
injury rate in $\mathrm{RRP}$ is $0-1.6 \%$, this rate is $<0.5 \%$ in $\operatorname{RARP}(59,61)$. Patel et al. defined 2 intraoperative complications (0.4\%), which were both rectal injuries in the first 25 cases. Authors report that they repaired the rectal injury in 3 layers with robotic aid (55).

The most specific complications of RARP are those that develop due to the robotic system. Any dysfunction or error of the robot has been reported to happen in $0.4 \%$ to $3 \%$ of the procedures (62). Andonian et al. report that in 50,000 RARPs performed in US between 2000 and 2007, there were robotic system dysfunctions in 168 of the cases (63). Of the dysfunctions, 94\% resulted in the conversion to open surgery in 2003; this has declined to $16 \%$ in 2007. Badani et al. report encountering technical issues in $0.2 \%$ ( 5 cases) of the cases; the issue was resolved in 2 of them by restarting the system, in 2 with technical support from the provider, and in 1 by using another robotic system that was present (37). Patients should be informed about this possibility preoperatively, and a decision needs to be made on how to handle such an issue (open surgery, laparoscopic radical nephrectomy -LRN-, or postponing the operation).

\section{Postoperative}

Postoperative complications are complications specific to surgery or those that can be observed in any surgery. According to this, deep vein thrombosis rates are $1.1-7.8 \%$ and $0-2.2 \%$ for RRP and RARP. While almost no ileus has been reported in RRP, this rate is $0-2.5 \%$ in RARP. Anastomotic leak rates for RRP and RARP are $0.1-21.7 \%$ and $0-4.4 \%$ respectively. These rates reflect that anastomosis can be performed more safely and leak-proof in RARP. Bladder neck stenosis occurs in $0.5-9 \%$ of RRP and in $0.5-1.6 \%$ of RARP cases. A complication specific to RARP is bleeding or hernia from port site, which occur in $0-2.2 \%$ of cases (12).

The meta-analysis by Novara et al on the perioperative results and complications post-RARP reports that the operation duration decreases and the rates of blood loss and transfusion decline with routine performance of RARP. High BMI, large prostate volume, prior abdominal surgery interventions or interventions for benign prostate hyperplasia, and presence of middle lobe are reported to complicate RARP, prolong duration of surgery, and increase blood loss and catheterization duration. Additionally, the surgeon's experience is important in terms of perioperative results and complications while patient characteristics (PSA, biopsy Gleason score, comorbidities) play an important role for these results and complications as well. The rates of blood loss and transfusion are lower compared to open radical prostatectomy and laparoscopic radical prostatectomy (64).

\section{Costs}

Compared to open radical surgery, RARP is a more expensive treatment method. A rough estimate for its main costs are \$1.2 million for the robot and its set up, $\$ 100.000$ for annual maintenance, and $\$ 1.500$ for disposable tools used per patient. There are also costs of the tools specified by the provider that can be used for a limited number of times (reposables). With advantages like shorter hospital stay and lower rates of blood transfusion over RRP, such factors do not lower costs significantly enough that the two methods could be more comparable (65). The average cost of RARP per patient is $\$ 5.410$ while it is $\$ 1.870$ for RRP. This makes the RARP method three times as expensive as RRP (9).
However, in centers where RARP is performed numerous times (more than 10 cases per week), the cost gap between RRP and RARP narrows (66). With the expected decreases in the prices of the robotic systems and the costs of the tools used, the cost gap between the two methods will be further narrow. Loton et al. examined the cost differences between the two modes and reported an estimate of \$857 robotic processing system cost and \$1705 instrument cost per patient (67). Menon reported that for US to have more reasonable robot cost, there should be at least 75 cases per year with a maximum of 3 hours per case (68). When Burges et al. compared costs of RRP and RARP, they reported that especially with the first 20 case the cost gap is larger due to the impact of learning curve (69). Steinberg et al. studied the impact of the learning curve on costs, and reported that the costs associated with a 360 patient learning period (longest term) were approximately $\$ 1.3$ million and those associated with a 24-patient learning term (the shortest term) was approximately $\$ 950.000$. The necessary number of cases for the learning curve varies, with reported case range of 13-200 in the literature. When an average of 72 cases is considered, costs of this period are estimated at \$217.034 (70).

\section{Trifecta and Pentafecta Effect}

Bianco et al. from Memorial Sloan Kettering Cancer Institute defined the trifecta effect as reaching the desired target post-radical prostatectomy (being cancer-free, potent, and continent) (71). When they examined 1746 patients who underwent RRP, they determined a $60 \%$ rate of trifecta effect. Eastham et al. reported this rate as $62 \%$ in a RRP series of 1577 patients (72). When the trifecta effect was measured for RARP, Patel et al. reported a 91\% rate of trifecta effect on the 18th month (73).

Patel et al. also defined a novel evaluation model named pentafecta effect. In this model, in addition to the trifecta effect, not having postoperative complications and having negative surgical margins were added to the parameters. In an 1111-patient RARP series, Patel et al. report continence, potency, survival without biochemical recurrence, and 12th month trifecta rates as 94.6\%, 89.8\%, 96.4\% and $83.1 \%$. They reported that $94.3 \%$ of these patients did not have post-operative complication, $90.7 \%$ had negative surgical margins, and the pentafecta rate for the 12th month was 70.8\% (74).

This evaluation method is expected to become a resource for providing correct information to meet the needs of patients who will undergo a minimally invasive surgery for prostate cancer.

\section{Comparison of Radical Perineal Prostatectomy with Other Methods}

Particularly in recentyears, the number of laparoscopic and robotic radical prostatectomies almost reached, even surpassed in some places, the number of open radical prostatectomies. We believe that it is important to draw attention to radical perineal prostatectomy (RPP), popularity of which has never been as high as radical prostatectomy, since the surgical techniques of our day are defined as minimally invasive, and to compare it with other methods. RPP is a considerable alternative to all retropubic, robotic or laparoscopic radical prostatectomies. Perineal radical prostatectomy was first defined by Hugh Hampton Young in 1904 for prostate cancer (75). In 1942, Belt defined sub-sphincter entry to the pelvis and the early dissection of seminal vesicles and vas. 
Afterwards, following Walsh's report on the cavernous nerve bundles and that they were not damaged during radical prostatectomy, Weldon placed nerve-sparing RPP on the agenda in 1988 (75).

\section{Patient Selection}

Among the main indications for RPP are having a 10-year life expectancy, PSA $<10 \mathrm{ng} / \mathrm{mL}$, Gleason score $<7$, and not having lymph-node positivity. In patients suspected of lymph node positivity, it can be carried out in combination with laparoscopic pelvic lymphadenectomy. RPP may be performed in almost all patients including those with high body mass index, history of abdominal surgical intervention, renal transplantation, Superior vena cava syndrome, and other prostate-related surgeries without any problems. RPP may be preferred instead of retropubic radical prostatectomy in patients who have history of inguinal hernia operation and synthetic mesh placement. RPP is mainly contraindicated in patients with severe ankylosis and/or knee replacement preventing the extreme positioning of the patient for lithotomy. While there is no clear association between RPP and prostate size, it is an option to reduce the prostate size via transurethral prostate resection among patients with large volume prostate prior to operation $(75,76)$.

\section{Duration of Surgery}

In Impertore et al's study the average RPP duration was 122 minutes (59 patients) among patients who had undergone prostate surgery before, and it was 140 minutes (59 patients) in the ARP group. A statistically significant difference was found between the two methods in terms of duration of surgery $(p<0.001)(76)$.

\section{Blood Loss and Transfusion}

In Comploj and Harris's series, blood loss in RPP was minimal and none of the patients needed transfusion. Harris suggested 1-unit blood to be drawn from the patient prior to the surgery and in case of a potential needed of transfusion autologous transfusion during surgery would suffice $(75,77)$.

\section{Post-operative Pain}

RPP, compared to open radical prostatectomy and robotic radical prostatectomy is a superior method in terms of post-operative pain and analgesic use. Schmeller and Paiva reported that no analgesics were needed starting from post-operative day 2 . We believe that it does not lead to common pain issues experienced after a robotic prostatectomy (such as delays in return of the bowel movements) due to the small incision size, that the location of incision is not directly involved in mobilization, and the lack of abdominal gas insufflation $(78,79)$.

\section{Duration of Hospital Stay}

In a study by Prasad et al., comparing the post-RPP hospital stay, with other methods, they reported that the average stay after RPP was 2 days, while it was 3 days for the other methods, and that there was a statistically significant difference between them $(p<0.001)(80)$. Impertore et al's study comparing RPP and ARP among patients with prostate surgery history reports that there is no difference between the two with respect to duration of hospital stay (7.5 vs. 7.6 days) (76). In Harris's 907-patient series, the average duration of hospital stay was 1.1 days (75).

\section{Duration of Catheterization}

A study by Impertore et al. showed that duration of catheterization was shorter in the RPP group, compared to the ARP group (7.7 vs. 9.1 days, $p<0.001)(76)$. A study by Comploj et al. on the other hand reported that the need for recatheterization was higher among RPP group compared to the ARP and RARP, due to urinary retention development after the catheter was removed (77). Schmeller et al. have also found the catheterization lasted longer in the RPP group compared to the other methods (10 vs. 7 days on average) (78). Harris reported that in the RPP group, the patients received a cystogramon post-operative day 5 and had their catheter removed on day 8 (75).

\section{Oncological Findings}

Weldon et al. stated that the surgical margin positivity was between $15-44 \%$ in RPP. The surgical margin positivity rates based on the localization in this study were $25 \%, 7 \%$, and $16 \%$ for anterior, apex, and posterolateral surgeries, respectively (81). Comploj et al, in a 212-patient RPP group, reported the surgical margin positivity as $22 \%$ and that no biochemical recurrence occurred in $62 \%$ of these patients throughout their 48 month (6-117 months) follow-up on average (77). Paulson on the other hand reported that only 20\% of the patients with surgical margin positivity did not experience biochemical recurrence (82). Based on the 5-year follow-up results on a 704-patient RPP group, Harris reported the biochemical recurrence-free survival rates to be $94.5 \%, 80 \%$, and $81 \%$ for patients with organ-limited diseases, specimen-limited diseases, and surgical margin positivity (75). Surgical margin positivity was observed most frequently in the prostate apex in RPP groups. Especially the use of a bilateral nerve-sparing approach during RPP is known to be a factor affecting surgical margin positivity. A comparison of surgical margin positivity among patients with prostate surgery history by Impertore et al. reported that the rates were 10\% for the RPP and 25\% in the ARP group (76).

\section{Continence}

Comploj et al. reported 81\% complete dryness in a 48-month followup for the RPP group (77). Schmeller et al. have also reported that the continence rates were higher in the RPP group compared to the other methods (78). In the 704-patient series, Harris reported postoperative continence rates in $1 \mathrm{st}, 3 \mathrm{rd}$, 6th and 12th months as 52\%, $71 \%, 85 \%$, and $94 \%$, respectively (75). Continuous suture anastomosis is thought to play a role in the high rates of continence in RPP.

\section{Erectile Function}

Harris reported the rates of spontaneous erection and ability to have a sexual intercourse at the end of the first year in patients who had bilateral nerve-sparing RPP in the 907-patient series as 97\% and 80 $\%$, respectively. Harris also reported that, as opposed to the other radical prostatectomy operations, after the postoperative month 12 , the bilateral nerve-sparing was not superior to unilateral nervesparing, but it may be advantageous before then. In Prasad et al.'s 
study, the need for additional procedures due to erectile dysfunction in the RPP groups was found to be lower than the other minimally invasive methods used to treat prostate cancer (80).

\section{Complications}

Considering the complications of RPP, Bishoff et al. reported that fecal escape was greater in the RPP patients compared to those undergoing other methods. However, in those RPPs, the posterior end of the perineal incision approached the anal orifice by up to $2 \mathrm{~cm}$ (83). Fecal incontinence, fecal urgency or gas-passing during Valsalva maneuver was observed in the RPP group in Comploj et al.'s study (77). In the704-patient RPP series of Harris, fecal incontinence was observed in 1 patient, and 2\% of the patients had a gas-passing issue related to Valsalva (75). Again, in the RPP group, infection around the scar and opening of the scar was also observed more frequently, compared to the ARP and other minimally invasive methods (78). In Harris's series the rates of narrowing of the distal urethra and anastomosis post-RPP were reported to be $0.5 \%$ and $1 \%$, respectively (75). The most common complication in RPP is lower extremity neuropraxia development due to the patient's position. Price et al. reported the rate of lower extremity neuropraxia due to severe lithotomy position as $21 \%$ (84).

\section{Costs}

RPP, especially compared to RAPP, can be much more advantageous in terms of costs. Harris compared the cost of 3 methods (RPP, RRP, and RARP) and reported the average costs of RPP, RRP, and RARP as $\$ 11.600, \$ 34.000$, and $\$ 42.000$ (75). Prasad et al., have also compared RPP with other methods with respect to the post-operative period hospital admission costs (post-operative issue and complication related admissions) and found it to be cheaper by approximately $\$ 1.500$ (80). Especially in countries with low economic status, localized prostate cancer treatment with RPP is a cheaper and more suitable treatment option compared to RRP and RARP.

\section{Conclusion}

The number of prostate cancer diagnoses has increased especially with increased used of PSA.

Surgical removal of the prostate is considered the most effective treatment method for localized prostate cancer. Better understanding of the prostate anatomy and both the functions and the relations of neurovascular bundles with the prostate and developments in the surgical techniques within this respect have positively impacted the outcomes of radical prostatectomy regardless of the method used.

The minimally invasive treatment methods considered for prostate cancer lead to research in surgical methods and use of laparoscopy for this purpose. However, because the laparoscopic radical prostatectomy learning curve is long and it is a technically difficult surgical method, its use has remained relatively limited. Development of robotic systems and use of these systems in operations is the beginning of a new era in treatment. We believe that the advantages brought along with robotic systems have hindered widespread use of laparoscopic radical prostatectomy.

The purpose of RARP is to combine RRP's effectiveness and minimally invasive surgery advantages oncologically and functionally, and to prevent the difficulties experienced with laparoscopic radical prostatectomy. In addition, fast recovery, shorter hospital stay, less blood loss and lower rates of transfusion, and quicker return to daily functioning constitute some of the goals of the procedure. Starting in 2012, data supporting RARP's success in attaining these goals have increased. An indication of this is that many radical prostatectomies use robotic aid now. The cost gap between the two methods is expected to be eliminated with decreasing costs of the tools used and the higher availability of the robotic systems.

On the other hand RPP is one of the oldest surgical methods for prostate cancer treatment, the application of which has declined especially in the past 30 years. However, new studies on this method point out that RPP is not only one of the minimally invasive methods, but that it is also a method comparable with other methods in terms of oncological and functional results and a considerably advantageous one in terms of cost. RPP is a method that should definitely be considered in surgical treatment of early stage prostate cancer and should be in the armamentarium of surgeons of uro-oncology. Still there is need for further comparison of especially the three methods (RPP, RRP, and RARP) in prostate cancer treatment with more patients and longer follow-up periods.

\section{Conflicts of Interest}

There are no conflicts of interest.

\section{References}

1. Ferlay J, Shin HR, Bray F, Forman D, Mathers C, Parkin DM. Estimates of worldwide burden of cancer in 2008: GLOBOCAN 2008. Int J Cancer 2010;127:2893-2917.

2. Jemal A, Siegel R, Ward E, Murray T, Xu J, Thun MJ. Cancer statistics, 2007. CA Cancer J Clin 2007;57:43-66.

3. Platz EA, Giovannucci E. Prostate cancer. In: Schottenfeld D, Fraumeni JF, editors. Cancer epidemiology and prevention. New York, NY: OxfordUniversityPres; 2006. p. 1128-1150.

4. Center MM1, Jemal A, Lortet-Tieulent J, Ward E, Ferlay J, Brawley O, Bray F. International variation in prostate cancer incidence and mortality rates. Eur J Urology 2012;61:1079-1092.

5. Smith AJ. Principles of open radical prostatectomy: Applied to Roboticassisted laparoscopic prostatectomy. In: Smith AJ, Tewari AK, editors. Robotics in urologic surgery. Philadelphia, PA: Saunders Elsevier; 2008. p. 69-78.

6. Djavan B, Eckersberger E, Finkelstein J, Sadri H, Farr A, Apolikhin O, Lepor $H$. Oncologic, functional and cost analysis of open, laparoscopic and robotic radical prostatectomy. EurUrol Supp 2010;9:371-378.

7. Middleton RG, Thompson IM, Austenfeld MS, Cooner WH, Correa RJ, Gibbons RP, Miller HC, Oesterling JE, Resnick MI, Smalley SR, et al. Prostate cancer clinical guidelines panel summary: report on the management of clinically localized prostate cancer. J Urol 1995;154:2144-2148.

8. Walsh PC. Anatomic radical prostatectomy: Evolution of the surgical technique. J. Urol 1998;160:2418-2424.

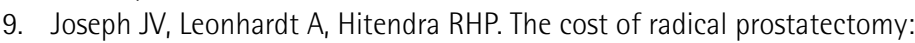
retrospective comparison of open, laparoscopic and robot-assisted approaches. J Robotic Surg 2008;2:21-24.

10. Nelson JB. Debate: open radical prostatectomy vs. laparoscpic vs. robotic. UrolOncol 2007;25:490-493.

11. Abbou CC, Hoznek A, Solomon L, Olsson LE, Lobontiu A, Saint F, Cicco A, Antiphon $\mathrm{P}$, Chopin D. Laparoscopic radical prostatectomy with a remote controlled robot. J Urol 2001;165:1964-1966. 
12. Shah SR, Patel VR: Perioperative outcomes of robotic radical prostatectomy. In: Smith A.J, Tewari A.K, editors. Robotics in urologic surgery. Philadelphia, PA: Saunders Elsevier; 2008. p. 91-99.

13. Lee DI. Robotic prostatectomy: what we have learned and where we are going. Yonsei Med J 2009;50:177-181.

14. Brown JA, Rodin DM, Lee B, Dahi DM. Laparoscopic radical prostatectomy and body mass index: an assessment of 151 sequential cases. J Urol 2005; 173:442-445.

15. Badani KK, Fumo MJ, Menon M. Vattikuti Institute prostatectomy (VIP) technique and current analysis of results. In: Smith A.J, Tewari A.K, editors. Robotics in urologic surgery. Philadelphia, PA: Saunders Elsevier; 2008. p. 55-67.

16. Singh A, Fagin $R$, Shah $G$, Shekarriz B. Impact of prostate size and body mass index on perioperative morbidity after laparoscopic radical prostatectomy. J Urol 2005;173:552-554.

17. Ahlering TE, Skarecky D, Lee D, Clayman RV. Succesful transfer of open surgical skills to a laparoscopic environment using a robotic interface: initial experience with laparoscopic radical prostatectomy. J Urol 2003;170:1738-1741.

18. Menon M, Shrivastava A, Tewari A, Sarle R, Hemal A, Peabody JO, Vallancien G. Laparoscopic and robot assisted radical prostatectomy: establishment of a structured program and preliminary analysis of outcome. J Urol 2002; 168:945-949.

19. Patel VR, Tully AS, Holmes $R$, Linday J. Robotic radical prostatectomy in the community setting: the learning curve and beyond: initial 200 cases. J Urol 2005;174:269-272.

20. Rocco B, Matei DV, Melegari S, Ospina JC, Mazzoleni F, Errico G, Mastropasqua M, Santoro L, Detti S, de Cobelli 0. Robotic vs open prostatectomy in a laparoscopically naive centre: a matched-pair analysis. BRU Int 2009;104:991-995.

21. Ahlering TE, Woo D, Eichel L, Lee DI, Edwards R, Skarecky DW. Robotassisted versus open radical prostatectomy: a comparison of one surgeon's outcomes. Urology 2004;63:820-822.

22. Krambeck AE, DiMarco DS, Rangel $\sqcup$, Bergstralh EJ, Myers RP, Blute ML, Gettman MT. Radical prostatectomy for prostatic adenocarcinoma: a matched comparison of open retropubic and robot-assisted techniques. Br J Urol 2009;103:448-453.

23. Ficarra V, Novara G, Fracalanza S, D'Elia C, Secco S, lafrate M, Cavalleri S, Artibani W. A prospective, nonrandomized trial comparing robot-assisted laparoscopic and retropubic radical prostatectomy in one European institution. Br J Urol 2009;194:534-539.

24. Carlsson S, Nilsson AE, Schucmacher MC, Jonsson MN, Volz DS, Steineck G, Wiklund PN. Surgery-related complications in 1253 robot-assisted and 485 open retropubic radical prostatectomies at the Karolinska University Hospital, Sweden. Urology 2010;75:1092-1097.

25. Tewari A, Srivasatava A, Menon M. Members of the VIP Team. A prospective comparison of radical retropubic and robot assisted prostatectomy: experience in one institution. BJU Int 2003;92:205-210.

26. Webster TM, Herrell SD, Chang SS, Cookson MS, Baumgartner RG, Anderson LW, Smith JA Jr. Robotic assisted laparoscopic prostatectomy versus radical retropubic prostatectomy: assessment of perioperative pain. J Urol.2005;174:912-914.

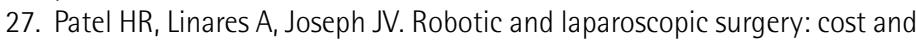
training. Surg Oncol 2009;18:242-246.

28. Menon M, Tewari A, Baise B, Guillonneau B, Vallancien G. Prospective comparison of radical retropubic prostatectomy and robot-assisted anatomic prostatectomy: the Vattikuti Urology Institute experience. Urology 2002;60:864-868.

29. Cathelineau $X$, Rozet $F$, Vallancien G. Robotic radical prostatectomy: the European experience. Urol Clin North Am 2004;31:693-699.

30. Brandina R, Berger A, Kamoi K, Gill IS. Critical appraisal of robotic-assisted radical prostatectomy. Current Opinion in Urology 2009;19:290-296.
31. Zincke $H$, Bergstralh EJ, Blute ML, Myers RP, Barrett DM, Lieber MM, Martin SK, Oesterling JE. Radical prostatectomy for clinically localized prostate cancer: long term results of 1143 patients from a single institution. J Clin Oncol 1994;12:2254-2263.

32. Hull GW, Rabbani F, Abbas F, Wheeler TM, Kattan MW, Scardino PT. Cancer control with radical prostatectomy alone in 1000 consecutive patients. J Urol 2002;167:528-534.

33. Weider JA, Soloway MS. Incidence, etiology, location, prevention and treatment of positive surgical margins after radical prostatectomy fpr prostate cancer. J Urol 1998;160:299-315.

34. Patel VR, Shah SR, Arend D. Histopathologic outcomes of robotic radical prostatectomy. Sci World J 2006;6:2566-2572.

35. DiMarco DS, Ho KL, Leibovich BC. Early complications and surgical magrin status following radical retropubic prostatectomy (RARP) compared to robot-assisted laparoscopic prostatectomy (RALP). J Urol 2005;173:277.

36. Smith JA Jr, Chan RC, Chang SS, Herrell SD, Clark PE, Baumgartner R, Cookson MS. A comparison of the incidence and location of positive surgical margins in robotic assisted laparoscopic radical prostatectomy and open retropubic radical prostatectomy. J Urol 2007;178:2385-2390.

37. Badani KK, Kaul S, Menon M. Evolution of robotic radical prostatectomy: assessment after 2766 procedures. Cancer 2007;100:1951-1958.

38. Jaffe J, Castellucci $S$, Cathelineau $X$, Harmon J, Rozet F, Barret E, Vallancien G. Robot-assisted laparoscopic prostatectomy: a single institutions learning curve. Urology 2008;73:127-133.

39. Novara G, Ficarra $V$, Mocellin $S$, Ahlering $T E$, Carroll $P R$, Graefen $M$, Guazzoni $G$, Menon $M$, Patel VR, Shariat SF, Tewari AK, Van Poppel $H_{\text {, }}$ Zattoni F, Montorsi F, Mottrie A, Rosen RC, Wilson TG. Systematic review and meta-analysis of studies reporting oncologic outcome after robotassisted radical prostatectomy. Eur Urol 2012;62:382-404.

40. Cooperberg MR, Kane CJ, Cowan JE, Carroll PR. Adequacy of lymphadenectomy among men undergoing robot-assisted laparoscopic radical prostatectomy. Br J Urol 2009;105:88-92.

41. Yee DS, Katz DJ, Godoy G, Nogueira L, Chong KT, Kaag M, Coleman JA. Extended pelvic lymph node dissection in robotic-assisted radical prostatectomy: surgical technique and initial experience. Urology 2010;75:1199-1204.

42. Atug F, Castle EP, Srivastav SK, Burgess SV, Thomas R, Davis R. Prospective evaluation of concomitant lymphadenectomy in robot-assisted radical prostatectomy: preliminary analysis of outcomes. J Endourol 2006;20:514-518.

43. Wilson T, Torrey R. Open versus robotic-assisted radical prostatectomy: which is beter?.Curr. Opinion in Urology 2011;21:200-205.

44. Geary ES, Dendinger TE, Frieha FS, Stamey Ta. Incontinence and vesical neck strictures following radical retropubic prostatectomy. Urology 1995;45:1000-1006.

45. Walsh PA, Marschke P, Ricker D, Burnett AL. Patient-reported urinary continence and sexual function after anatomic radical prostatectomy. Urology 2000;55:58-61.

46. Penson DF, McLerran D, Feng Z, Li L, Albertsen PC, Gilliland FD, Hamilton A, Hoffman RM, Stephenson RA, Potosky AL, Stanford JL. 5-year urinary and sexual outcomes after radical prostatectomy: results from the prostate cancer outcomes study. J Urol 2005;173:1701-1705.

47. Frota R, Turna B, Barros R, GIll IS. Comparison of radical prostatectomy techniques: open, laparoscopic and robotic assisted. Int Braz J Urol 2008;34:259-269.

48. Lepor H, Kaci L, XueX. Continence following radical retropubic prostatectomy using self-reporting instruments. J Urol 2004;171:1212-1215.

49. Pasticier G, Rietbergen JB, Guillonneau B, Fromont G, Menon M, Vallancien G. Robotically assisted laparoscopic radical prostatectomy: feasibility study in men. Eur Urol 2001;40:70-74.

50. Binder J, Kramer W. Robotically-assisted laparoscopic radical prostatectomy. BJU Int 2001;87:408-410. 
51. Menon M, Hemal AK, Tewari A, Shrivastava A, Bhandari A. The technique of apical dissection of the prostate and urethrovesical anastomosis in robotic radical prostatectomy. BJU Int 2004;93:715-719.

52. Ahlering TE, Eichel L, Edwards R, Skarecky DW. Impact of obesity on clinial outcomes in robotic prostatectomy. Urology 2005;65:740-745.

53. Quinlan DM, Epstein GI, Carter BS, Walsh PC. Sexual function following radical prostatectomy: influence of preservation of neurovascular bundles. J Urol 1991;145:998-1002.

54. Catalona WJ, Carvalhal GF, Mager DE, Smith DS. Potency, continence and complication rates in 1870 consecutive radical retropubic prostatectomies. J Urol 1999;162:433-438.

55. Patel VR, Thaly $R$, Shah K. Robotic radical prostatectomy: outcomes of 500 cases. BJU Int 2007;99:1109-1112.

56. Menon M, Tewari A. Vattikuti Institute Prostatectomy Team: Robotic radical prostatectomy and the Vattikuti Urology Institute technique: An interim analysis of results and technical points. Urology 2003;61:10-20.

57. Eastham JA. Robotic-assisted prostatectomy: is there truth in advertising? Eur Urol 2008;54:720-722.

58. Ficarra $V_{1}$ Novara $G$, Ahlering $T E$, Costello $A$, Eastham JA, Graefen $M_{1}$ Guazzoni G, Menon M, Mottrie A, Patel VR, Van der Poel H, Rosen RC, Tewari AK, Wilson TG, Zattoni F, Montorsi F. Systematic review and meta analysis of studies reporting potency rates after robot-assisted radical prostatectomy. Eur Urol 2012;62:418-430.

59. Gheiler EL, Lovisolo JA, Tiguert R, Tefilli MV, Grayson T, Oldford G, Powell IJ, Famiglietti G, Banerjee M, Pontes JE, Wood DP Jr. Results of clinical care pathway for radical prostatectomy patients in an open hospitalmultiphysician system. Eur Urol 1999;35:210-216.

60. Menon M, Tewari A, Peabody JO, Shrivastava A, Kaul S, Bhandari A, Hemal AK. Vattikuti Institute Prostatectomy, a technique of robotic radical prostatectomy for management of localized carcinoma of the prostate: experience over 1100 cases. Urol Clin North Am 2004;31:701-717.

61. Fischer $B$, Engel N, Fehr JL, John H. Complications of robotic assisted radical prostatectomy. World j Urol 2008;26:595-602.

62. Zorn KC, GofritON, Orvieto MA, Mikhail AA, Galocy RM, Shalhav AL, Zagaja GP. Da Vinci robot error and failure rates: single institution experience on a single three- arm robot unit of more than 700 consecutive robot-assisted laparoscopic radical prostatectomies. J Endourol 2007;21:1341-1344.

63. Andonian S, Okeke Z, Okeke DA, Rastinehad A, Vanderbrink BA, Richstone $L$, Lee BR. Device failures associated with patient injuries during robotassisted laparoscopic surgeries: a comprehensive re-view of FDAMAUDE database. Can J Urol 2008;15:3912-3916.

64. Novara G, Ficarra V, Rosen RC, Artibani W, Costello A, Eastham JA, Graefen M, Guazzoni G, Shariat SF, Stolzenburg JU, Van Poppel H, Zattoni F, Montorsi F, Mottrie A, Wilson TG. Systematic review and meta-analysis of perioperative outcomes and complications after robot-assisted radical prostatectomy. Eur Urol 2012;62:431-452.

65. Bivalacqua TJ, Pierorazio PM, Su LM. Open, laparoscopic and robotic radical prostatectomy: optimizing the surgical approach. Surg Oncol 2009;18:233-241.

66. Patel HR, LinaresA, Joseph JV. Robotic and laparoscopic surgery: cost and training. Surg Oncol 2009;18:242-246.

67. Lotan Y, Cadeddu JA, Gettman MT. The new economics of radical prostatectomy: cost comparison of open, laparoscopic and robot assisted techniques. J Urol 2004;172:1431-1435.
68. Menon M, Shrivastava A, Tewari A. Laparoscopic radical prostatectomy: conventional and robotic. Urology 2005;66:101-104.

69. Burgess SV, Atug F, Castle EP, Davis R, Thomas R. Cost analysis of radical retropubic, perineal and robotic prostatectomy. J Endourol 2006;20:827830.

70. Steinberg PL, Merguerian PA, Bihrle W 3rd, Seigne JD. The cost of learning robotic-assisted prostatectomy. Urology 2008;72:1068-1072.

71. Bianco FJ Jr, Scardino PT, Eastham JA. Radical prostatectomy: long term cancer control and recovery of sexual and urinary function (trifecte). Urology 2005;66:83-94.

72. Eastham JA, Scardino PT, Kattan MW. Predicting an optimal outcome after radical prostatectomy: the trifecta nomogram. J Urol 2008;179:22072210.

73. Patel VR, Coelho RF, Chauhan $S$, Orvieto MA, Palmer KJ, Rocco $B$, Sivaraman A, Coughlin G. Continencei potency and oncological outcomes after robotic-assisted radical prostatectomy: early trifecta results of a high volume surgeon. Br J Urol 2010;106:696-702.

74. Patel VR, Sivaraman $A$, Coelho RF, Chauhan $S$, Palmer KJ, Orvieto MA, Camacho I, Coughlin G, Rocco B. Pentafecta: A new concept for reporting outcomes of robot-assisted laparoscopic radical prostatectomy. Eur Urol 2011;59:702-707.

75. Haris MJ. The Anatomic Radical Perineal Prostatectomy: An OutcomesBasedEvolution. Eur Urology 2007;52:81-88.

76. Imperatore $V$, Cantinello $F$, Fusco $F$, lannuzzo $M$, DiMeo $S$, Imbimbo $C$ Radical perineal prostatectomy versus radical retropubic prostatectomy after previous prostate surgery: surgical and functional outcomes. Urol Int 2011;86:140-145.

77. Comploj E, Pycha A. Experience with radical perineal prostatectomy in the treatment of localized prostate cancer. TherapeuticAdvances in Urology 2012;4:125-131.

78. Schmeller $N$, Keller $H$, Janetschek G. Head-tohead comparison of retropubic, perineal and laparoscopic radical prostatectomy. Int J Urol 2007;14:402-405.

79. 79.Paiva CS, Andreoni C, Cunha GP, Khalil W, Ortiz V. Differences among patients under going perineal or retropubic radical prostatectomy in pain and perioperative variables: a prospective study. BJU Int 2009;104:12191226.

80. Prasad SM, Gu X, Lavelle R, Lipsitz SR, Hu JC. Comparative effectiveness of perineal versus retropubic and minimally invasive radical prostatectomy. J Urol 2011;185:111-115.

81. WeldonVE, Tavel FR, Neuwirth H, Cohen R. Patterns of positive specimen margins and detectable prostate specific antigen after radical perineal prostatectomy. J Urol 1995;153:1565-1569.

82. Paulson DF Impact of radicalprostatectomy in themanagement of clinicallylocalizeddisease. J Urol 1995;152:1826-1830.

83. Bishoff JT, Motley G, Optenberg SA, Stein SR, Moon KA, Browning SM. Incidence of fecal and urinary incontinance following radical perineal and retropubic prostatectomy in a national population. J Urol 1998;160:454458.

84. Price DT, Vieweg J, Roland F, Coetzee L, Spalding T, Iselin C. Transient lower extremity neuropraxi aassociated with radical perineal prostatectomy: A complication of exaggerated lithotomy position. J Urol 1998;160:13761378. 